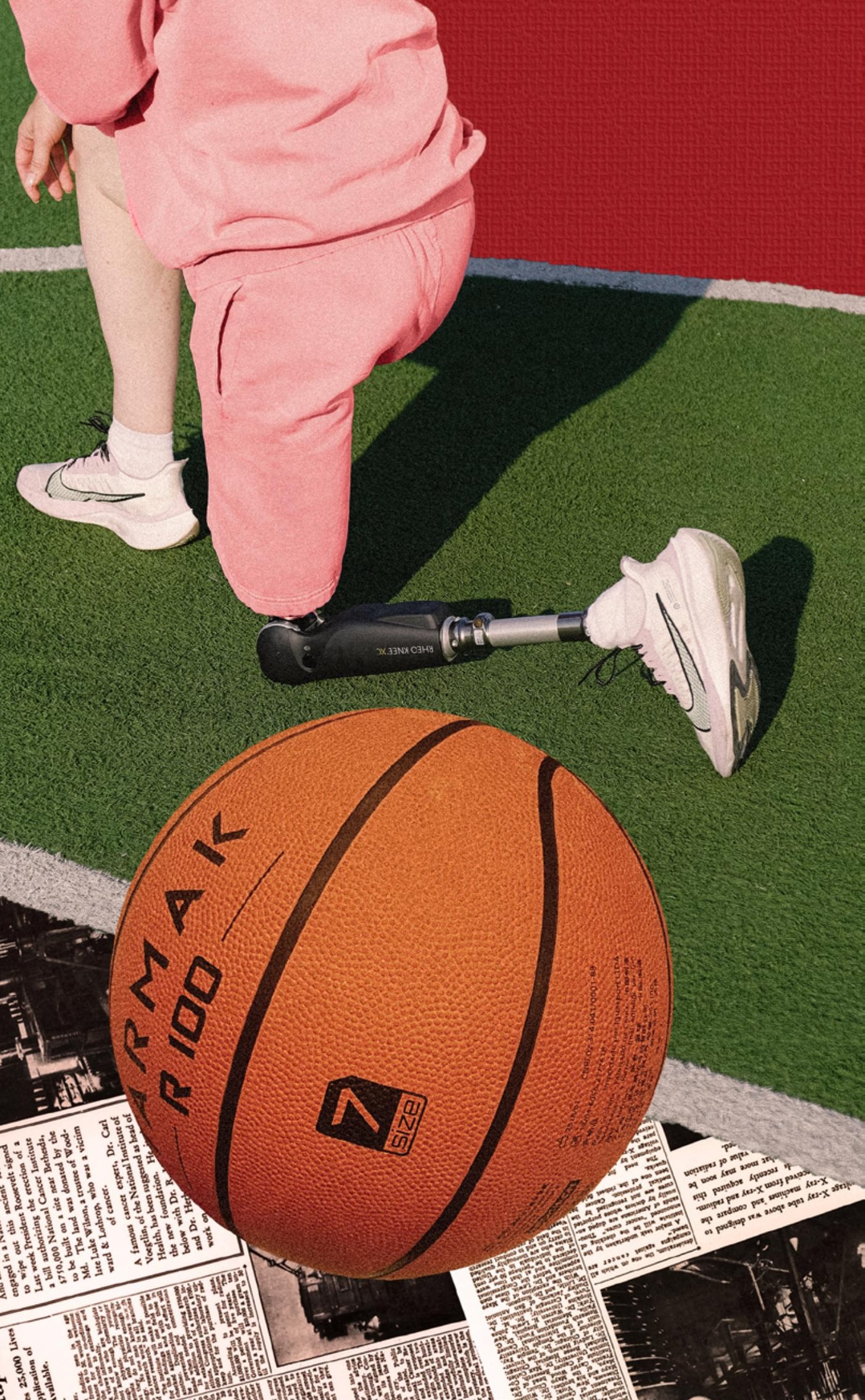




\section{Ações de formação, educação em saúde e acessabilidade no programa paradesporto da cidade de Blumenau}

\section{Training actions, health education and acessibility in the paradesport program in}

Blumenau

Rodrigo Diaz de Vivar y Soler Soler Professor de Psicologia e do Mestrado em Educação na Fundação Universidade Regional de Blumenau - FURB rsoler@furb.br

Anamaria Araujo da Silva Professora de Nutrição na Fundação Universidade Regional de Blumenau - FURB aas@furb.br

Aurélio Faustino Hoppe Professor de Ciências da Computação na Fundação Universidade Regional de Blumenau - FURB aureliof@furb.br

Luciana Bisio Mattos Professora de Psicologia na Fundação Universidade Regional de Blumenau - FURB

Imattos@furb.br

Stella Maris Martins Cruz Castelo de Souza Nemetz Professora de Arquitetura na Fundação Universidade Regional de Blumenau - FURB snemetz@furb.br

Carlos Roberto de Oliveira Nunes Professor de Psicologia na Fundação Universidade Regional de Blumenau - FURB carlosnunes@furb.com.br

Mahasiãh Raimundo Graduando em Psicologia Fundação Universidade Regional de Blumenau - FURB mraimundo@furb.br

Mateus Artur Pereira Nuss Graduando em Psicologia na Fundação Universidade Regional de Blumenau - FURB mnuss@furb.br

Andréia Nathalli Spiess Graduanda em Nutrição na Fundação Universidade Regional de Blumenau - FURB andreianspiess@gmail.com

Gabriela Frischknecht Graduanda de Nutrição na Fundação Universidade Regional de Blumenau - FURB gabfrischknecht@furb.br

Beatriz Germer Baptista Graduanda de Nutrição na Fundação Universidade Regional de Blumenau - FURB bbaptista@furb.br

Nathana Luana Hoffmann Graduanda de Nutrição na Fundação Universidade Regional de Blumenau - FURB nathanaluana@hotmail.com

Paola Ruana Haupt Graduanda de arquitetura na Fundação Universidade Regional de Blumenau - FURB phaupt@furb.br

Ruan Jupiaruma Dos Santos Scharf Graduando de Psicologia na Fundação Universidade Regional de Blumenau - FURB rjsscharf@furb.br

Giselle Margot Chirolli Coordenadora do Programa de Paradesporto de Blumenau giselli@blumenau.com.br 


\section{RESUMO}

Este artigo procura apresentar uma experiência de extensão desenvolvida entre os anos de 2018 e 2019 pelos cursos de Psicologia, Ciências da Computação, Nutrição e Arquitetura, junto ao Programa Paradesporto, desenvolvido na cidade de Blumenau. A partir de diversas ações multiprofissionais, essa experiência procurou intensificar estratégias voltadas para a formação, para a educação em saúde e para a acessibilidade de educadores, paratletas e familiares por meio da promoção da cidadania e da articulação entre a Universidade Regional de Blumenau e as demandas recolhidas pelos participantes do programa paradesporto. Destaca-se a importância e a necessidade dessas ações voltadas para o exercicio da cidadania das pessoas com deficiência, seus familiares e demais atores vinculados ao Programa Paradesporto em Blumenau.

Palavras-chave: Programa Paradesporto; educação em saúde; formação; acessibilidade; multiprofissionalidade.

\section{ABSTRACT}

This article seeks to present an extension experience developed between the years 2018 and 2019 by the Psychology. Computer Science, Nutrition and Architecture courses, along with the Paradesport Program developed in the city of Blumenau. Based on several multiprofessional actions, this experience sought to intensify strategies aimed at training, health education and the accessibility of educators, para-athletes and family members from a perspective of promoting citizenship and the articulation between the Regional University of Blumenau and the demands collected by the participants of the parasports program. It highlights the importance and need of these actions aimed at the exercise of citizenship of people with disabilities, their families and other actors linked to the Paradesport Program in Blumenau.

Keywords: Paradesport Program; health education; formation; accessibility; multiprofessionality. 


\section{INTRODUÇÃO}

Uma parcela significativa da população brasileira tem algum tipo de deficiência. De acordo com o Instituto Brasileiro de Geografia e Estatística - IBGE - no ano de 2010, 23.9 \% dos cidadãos brasileiros tinham, pelo menos, um tipo de deficiência, sendo que $2,4 \%$ das pessoas com idade entre 0 e 14 anos apresentavam uma deficiência severa (BRASIL, 2012).

Entende-se que sujeitos com deficiência são aqueles que apresentam algum tipo de limitação dos seus estados de natureza física, mental, intelectual, sensorial etc. que restringe a sua condição de acessibilidade ao mundo e as coisas em um sentido geral. Desse modo, essas limitações acabam por obstruir o rol de garantias fundamentais relacionadas à participação plena e efetiva do sujeito na vida em sociedade, contribuindo para a sua segregação, e assim, a impossibilidade de equidade em relação aos sujeitos considerados normais ${ }^{1}$

Historicamente, essa população, em nivel mundial, foi alvo de exclusão social. Isso se deu através da impossibilidade da participação nas esferas da vida social, tais quais a educação formal, o esporte e o lazer, sob a presunção de que a condição de deficiência é sinônimo de invalidez, ou seja, o sujeito com deficiência não teria função na vida social (Araújo, 1997).

Pode-se afirmar que as pautas politicas das pessoas com deficiência são muito recentes em nosso país. Somente no ano de 1999 é que foi homologada a primeira política nacional voltada para a integração da pessoa com deficiência. Tal política foi responsável por indicar as orientações relacionadas aos principais tópicos pertinentes aos conjuntos de critérios presentes nas deficiências. Isto é, esse documento regulamenta, por exemplo, a deficiência física como uma alteração completa ou parcial de um ou mais segmentos do corpo. Da mesma forma, estabelece que a deficiência auditiva corresponde a uma perda total ou parcial das possibilidades sonoras. Por fim, registra as questões relacionadas aos aspectos psicossociais em relação à deficiência mental. Desse modo, percebe-se que as diretrizes voltadas para a política das pessoas com deficiência corresponde aos seguintes aspectos: promoção da qualidade de vida, assistência integral à saúde, desenvolvimento de programas de prevenção às deficiências, ampliação e o fortalecimento de dispositivos de informação e de controle social, e, por fim, a ação conjunta do Estado e da sociedade civil, de modo a assegurar a plena integração da pessoa portadora de deficiência no contexto socioeconômico e cultural.

É neste contexto que, em 2018, foi desenvolvido o projeto "Ações de educação em saúde e acessibilidade para os participantes do Programa do Paradesporto Escolar de Blumenau". Este projeto estendeu-se e continuou em 2019 sob o título "Ações de Formação, Educação em Saúde e Acessibilidade para os Participantes do programa de Paradesporto Escolar de Blumenau". Neste está inclusa a responsabilidade de desenvolver ações de formação com os educa-

\footnotetext{
${ }^{1}$ Compreendemos a palavra normalidade como um conceito extremamente problemático, mas que serve para percebermos - principalmente a partir das contribuições de Foucault (1975) e Canguilhem (1995) - o que separa a normalidade da anormalidade a partir dos dispositivos de poder e das estratégias de saber presentes nas ciências humanas, sociais e biológicas.
} 
dores do Programa de Paradesporto Escolar de Blumenau (PPE). A composição do projeto em 2019 envolveu os cursos de Ciências da Computação, Arquitetura, Psicologia, Nutrição e Arquitetura. Todas as áreas trabalharam a partir de um elo comum: o empoderamento dos participantes do Programa de Paradesporto Escolar (PPE), tanto em se tratando das crianças com deficiências, como dos pais e educadores, por meio de oficinas, formações e outras atividades que serão citadas posteriormente.

O PPE na cidade de Blumenau foi fundado no ano de 2011, buscando introduzir os princípios de inclusão na cidade e trazendo a prática desportiva no contraturno escolar para o público-alvo de crianças e jovens de 1 a 19 anos de idade, matriculadas na rede escolar privada ou pública, as quais apresentasse qualquer tipo de deficiência (Machado, Chirolli \& Nunes, 2017).

Para melhor entender as relações com o poder público e as movimentações na trajetória que culminaram na criação do PPE, Machado, Chirolli \& Nunes (2017, p. 111) afirmam que:

\footnotetext{
No ano de 2012, foi fundada a Associação do Paradesporto Escolar de Blumenau (APESBLU) com o objetivo de apoiar o Projeto na captação de recursos. No ano de 2013, o PPE foi novamente apresentado à Secretaria Municipal de Educação de Blumenau (SEMED) e então aprovado, atingindo assim o principal objetivo desde a sua proposta em 2011, isto é, tornar-se uma ação pública institucional da SEMED para promoção de inclusão, abrangendo desde a educação infantil até o ensino médio. Assim, a partir de 2013, o PPE passou a ser desenvolvido de forma intersetorial pela SEMED, com o apoio da APESBLU, representando a sociedade civil organizada, e em parceria com diversas empresas e duas instituições de ensino superior, criando-se a corresponsabilização para uma sociedade mais inclusiva, com pleno exercício dos direitos
}

Em 2016 o programa contava com 254 alunos (Machado, Chirolli \& Nunes, 2017). Hoje, conta com aproximadamente 500 paratletas frequentadores de 65 polos espalhados por toda a cidade de Blumenau.

Foram realizadas, ao longo do período compreendido entre agosto de 2018 a fevereiro de 2020, as seguintes atividades: a) 24 sessões de educação em saúde com participantes do Programa Paradesporto Escolar. Os conteúdos e metodologias dessas atividades foram definidos em diálogos entre docentes responsáveis pelo projeto, acadêmicos (bolsistas e voluntários) e com educadores participantes do PPE, por meio de reuniões. B) Produção de materiais educativos relacionados a temas de alimentação saudável, cuidado em saúde, deficiência. C) Oficinas de formação relacionadas à educação em saúde em diferentes temas para os educadores que trabalham no PPE. D) Ações de acessibilidade relacionadas à construção de soluções arquitetônicas e urbanística viáveis, técnica e financeiramente, para as problemáticas identificadas pelos participantes do PPE. E) Desenvolvimento de soluções tecnológicas a fim de trazer dinamismo e facilidade para o cotidiano das pessoas com deficiência, cuidadores e profissionais da área relacionados ao programa. 
Apresentamos a seguir os resultados dessas intervenções em consonância com as referências, métodos e considerações articuladas às perspectivas de intervenção do projeto e as políticas voltadas para a promoção da cidadania dos deficientes.

\section{REVISÃO DE LITERATURA}

O século XIX foi a principal época em que políticas públicas se desenvolvem para estabelecer direitos aos deficientes, majoritariamente nos Estados Unidos e paises da Europa. Um princípio muito presente nessas políticas era o da reabilitação, seja como forma de aprendizagem funcional do organismo de uma pessoa após a perda de alguma forma de interação ambiental - por exemplo atividades como o esporte, de modo a inseri-los em atividades que Ihes possibilitassem o desenvolvimento de autoestima, condicionamento físico e criação de vínculos, beneficiando-os em dimensão biopsicossocial e ressignificando seu sentido de deficiente enquanto "inválido" (Araújo, 1997).

Além de responder a demanda de grupos sociais, também se deve compreender a inclusão de deficientes no esporte na perspectiva da saúde mental, entendendo que a condição de exclusão social oportuniza a autoconsciência dos individuos excluidos enquanto pessoas incapazes de exercer cidadania, o que impele a motivação para exercer uma conduta de autoafirmação e afirmação social (Sawaia, 1999). Sem mencionar as pressões que surgem em decorrência do desempenho esportivo tanto na aquisição de habilidades quanto na comparação com os outros membros do grupo.

Entre as principais linhas argumentativas que balizam a reflexão das práticas desportivas para pessoas com deficiência, as reflexões de Amaral (1994) são um marco importante a ser retomado. A autora supracitada buscou trabalhar a deficiência à luz de dois fatores principais, argumentando serem ambos fonte de problemas, e aponta para uma solução: a integração social e o desenvolvimento de potencialidades. O favorecimento ou não à emancipação dos deficientes estaria ligada a fenômenos emocionais, racionais e sociais que contingenciam o acesso dessas pessoas a essas problemáticas, e que se dão no contato entre três categorias de protagonismo social: o indivíduo, grupo e sociedade (Amaral, 1994).

Do ponto de vista da autora, partindo dessa perspectiva, o profissional não pode inserir-se no trabalho com deficientes somente como agente técnico, mas também como sujeito, visto que é impossivel separar-se um sujeito que exerce o papel de psicólogo da rede de influências sociais que é a responsável pelas mazelas acometidas sobre as pessoas com deficiência.

Amaral (1994) faz uma delineação entre "deficiência primária", ligada às próprias impossibilidades relacionadas diretamente com a anormalidade estrutural ou funcional do corpo, e "deficiência secundária", dizendo respeito aos juizos de valor feitos na comparação da pessoa com deficiência com outros membros de seu mesmo grupo, cultura, ambiente, possivelmente hostis. 
Medeiros, Diniz \& Barbosa (2010, p. 23) aplicam o conceito de "equidade" como fundamental para se pensar formas de integração social que contemplem pessoas com deficiência. Indicam que devem ser foco não as impossibilidades dos sujeitos, mas sim o que esses são capazes de fazer a partir de suas condições corporais, em termos de estrutura, função e habilidades. Isto faz parte da ideia do Paradesporto, que visa à adaptação de práticas de esporte e exercício, dando valor às potencialidades, e não às dificuldades da deficiência, considerando então a pessoa como ser ativo no mundo, no pleno "direito de estar no mundo". Possibilita, desta maneira, pensar as políticas públicas para além do olhar assistencialista e normalizador, através de um olhar potencializador.

O esporte deve ser compreendido, de acordo com Costa et al. (2013), como uma atividade eminentemente inclusiva que estimula a interação social e o senso de motivação para que seus participantes alcancem seus objetivos e também como um aspecto importante na perspectiva de tratar a inclusão de deficientes como um processo reabilitativo das capacidades psicomotoras e psicossociais enquanto forma de exercicio da imposição social. O esporte então traz novos horizontes de vida para o sujeito com deficiência, cheio de expectativas e possibilidades. No Brasil, o esporte para pessoas com deficiência, ou esporte adaptado, deve levar em consideração as próprias aptidões dos paratletas, interesse e domínio das regras de determinada modalidade de esporte, e suas capacidades individuais de comportamento motor. O profissional envolvido deve estar atento a esses pormenores para poder, assim, motivar os paratletas (Costa et al., 2013).

\section{DESCRIÇÃO DAS ATIVIDADES}

As atividades desenvolvidas pelos participantes do projeto foram realizadas nos polos desportivos do PPE que aceitaram receber as ações do projeto. Todos os métodos e objetivos das ações foram discutidos e apresentados anteriormente numa reunião que o PPE realiza mensalmente para a avaliação de suas atividades. As ações de 2018 e 2019 foram distribuídas entre os polos da Equitação Adaptada, da Bocha Adaptada, dois polos de natação, além de ações realizadas nas dependências da Fundação Universidade Regional de Blumenau (FURB) com os educadores da PPE. Cada grupo de bolsista e docentes do projeto ficou responsável por algum polo, onde foram aplicadas as seguintes propostas:

Oficinas de educação em saúde. Método: essas oficinas tiveram como objetivo a realização de ações voltadas para a educação em saúde por meio da articulação entre a equipe proponente e parte da população atendida pelo Programa Paradesporto. Ao todo, foram realizadas 26 intervenções, que contaram com a participação de pais e de alunos. Essas intervenções ocorreram na forma de oficinas descritas a seguir: 1) Ludoterapia. Essa abordagem objetiva o estímulo do participante. O trabalho lúdico com massinhas promove a dessensibilização focada no mutismo seletivo. 2) Jogo das situações. Esta atividade foi 
realizada no polo de equitação adaptada e tratou-se de um jogo de situações randômicas, que envolve situações em familia e, assim, promove a educação, a reflexão e a mediação de práticas parentais. A atividade promoveu a produção de uma mediação dialógica a partir das demandas trazidas pelos pais e produziu uma reflexão embasada nos fundamentos teóricos aprendidos na graduação de psicologia. Esta atividade foi de suma importância para agregar experiência no diálogo com pais, possibilitando a mediação dos conhecimentos teóricos da graduação como instrumento de reflexão para construção de modos de vida e nos estilos parentais. 3) Oficina de Música. A prática teve como finalidade promover a sensibilização e a criação musical de maneira lúdica. Foram produzidas músicas sobre o cotidiano da prática desportiva na Equitação Adaptada. 4) Oficina de Sentimentos e história. A finalidade foi igualmente promover a dessensibilização e educação emocional focada no mutismo seletivo. Isso foi proposto por meio da contação de história com instrumentos lúdicos para interação e aproximação. 5) Oficina de contação de histórias com fantoches. Essa atividade, como a anterior, teve como objetivo desenvolver ações de contação de história para a promoção da dessensibilização através da aproximação lúdica e educação emocional focada no mutismo seletivo. 6) Oficina de contação de história musicalizada e interativa. Essa oficina teve como finalidade promover uma atividade lúdica de sensibilização musical, envolvendo o ensino e instrução para usar o instrumento bongô através da criação e contação de história criada para esta oficina específica. 7) Oficina do Brinquedo maluco. Essa oficina foi responsável por promover um trabalho lúdico de dessensibilização e educação emocional entre pais e filhos. Os alunos, com ajuda dos pais, usaram a imaginação com de massinhas de modelar para criar um brinquedo com um superpoder inventado por eles. 8) Atividade de levantamento de informações sobre competências e dificuldades num polo de Bocha Adaptada de rendimento. A atividade foi realizada de maneira lúdica e adaptada, já que os alunos da bocha têm deficiências físicas severas. Os participantes tinham que quantificar uma autovisão de suas competências (ex: coragem, vontade, comunicação) por meio de feijões. 9) Oficina de mapa do atleta. Essa oficina foi oferecida com o intuito de procurar trazer à tona situações e sentimentos que os alunos vivenciavam na prática desportiva de rendimento e não eram verbalizadas para a equipe técnica e, por meio dessa exposição, elaborar a devida intervenção.

Atividades promovidas pela nutrição. 1) Montagem de pratos divertidos. Essa atividade foi proposta com o intuito de conhecer a realidade alimentar dos participantes da equitação e apresentar a eles a pirâmide alimentar. 2) Jogo da memória dos alimentos. O objetivo dessa intervenção foi mostrar aos alunos da equitação os alimentos que devem ser consumidos em menor quantidade. 3) Degustação de bolo com ingrediente secreto. Essa atividade teve como intuito mostrar aos participantes da equitação que há ingredientes diversos que podem servir, de forma criativa, para uma receita, e também promover a ideia do comer e fazer comida como um ato divertido e de infinitas possibilidades criativas. 4) Jogo de cartas sobre bons hábitos. Essa atividade teve como objetivo promover o diálogo com os participantes do polo da equitação adaptada sobre 
os hábitos saudáveis representados nas cartas. 5) Elaboração de questionário de frequência alimentar. Como o próprio nome representa, foi desenvolvido um questionário com a finalidade de conhecer a realidade alimentar dos participantes da modalidade da bocha adaptada a fim de desenvolver práticas que auxiliem na promoção de hábitos mais saudáveis. 6) Oficina sobre como montar um prato saudável. Esta oficina teve como finalidade explicar os grupos alimentares e suas respectivas proporções de consumo na pirâmide alimentar; analisar o consumo alimentar habitual de cada participante; incentivar o consumo consciente dos alimentos. 7) Oficina sobre chás. O objetivo foi o de trazer conhecimento aos participantes da equitação (pais, alunos e educadores), sobre os diferentes tipos de chás e seus benefícios no uso diário para o bem-estar. 8) Oficina sobre temperos. A finalidade dessa oficina foi mostrar os diferentes tipos de temperos para os participantes da equitação e promovendo a ideia de que é possivel cozinhar com sabor, mesmo com pouco sal, lançando mão da receita do sal verde. 9) Oficina do jogo da memória. Por meio dessa atividade, procurou-se verificar as preferências alimentares, compreender as várias dificuldades que levam os participantes a não experimentarem novos alimentos e também estimular a cognição e o comportamento motor dos participantes. Estes tinham que adivinhar em qual local o par da fruta/hortaliça se encontrava. 10) Experimentando frutas diferentes. Através desta oficina procurou-se estimular novas escolhas alimentares e mostrar que experimentar algo novo pode ser divertido e até surpreendente.

Atividades promovidas pela ciência da computação. 1) Solução de problemas tecnológicos. Essa atividade teve como objetivo a construção de materiais tecnológicos de apoio para solução de problemas de mídia no PPE. 2) Desenvolvimento de aplicativo. O objetivo foi usar o dinamismo das ferramentas tecnológicas em favor da acessibilidade. O aplicativo desenvolvido possibilita a sinalização em mapa online dos locais de Blumenau com acessibilidade inadequada. As informações são compiladas juntamente e guardadas num banco de dados no qual ficam guardados todos os locais que apresentam as devidas padronizações para as deficiências.

Atividades promovidas pela arquitetura. 1) Construção de projeto sobre banheiro adaptado. O objetivo foi o de desenvolver um projeto arquitetônico de um banheiro adaptado para promover acessibilidade para os alunos com deficiência física no polo de equitação. 2) Elaboração de cobertura do redondel (polo de equitação). A finalidade desse projeto é desenvolver uma cobertura do redondel no polo de equitação, a fim de tornar o espaço mais bem aproveitado para aulas em dias de chuva e sol intenso. 3) Projeto arquitetônico da sala de treino de tênis de mesa (polo de tênis de mesa). A atividade teve o intuito de propor o desenvolvimento de um projeto arquitetônico para organização do layout da sala de treino de tênis de mesa, de forma A influir positivamente na qualidade dos treinos e proporcionar um espaço mais confortável e acolhedor para os participantes do Programa de Paradesporto. 4) Elaboração de Cartilha de orientação de acessibilidade em casa. Esse material gráfico foi pensado como orientação sobre acessibilidade em residências para ser distribuido aos 
participantes do Programa Paradesporto e às famílias que estão envolvidas com ele.

\section{ANÁLISE DAS ATIVIDADES}

Nosso projeto integrou, por meio de uma perspectiva multiprofissional, os cursos de Arquitetura e Urbanismo, Nutrição, Psicologia e Ciência da Computação. A multiprofissionalidade, segundo Araújo et al. (2017), em propostas extensionistas, consiste em uma estratégia de potencialização dos aspectos de estreitamento de vínculo da Universidade com a comunidade. O objetivo geral do projeto foi promover intervenções multiprofissionais junto aos alunos com deficiência participantes do PPE, seus familiares e educadores do programa, por meio de ações de educação em saúde, formação e desenvolvimento de tecnologia e propostas sobre acessibilidade.

Para o desenvolvimento de cada atividade, foi definida uma equipe de docentes e discentes que trabalhou de forma conjunta, interagindo e colaborando entre si para o alcance de cada objetivo.

Esta interação se deu por meio de discussões, debates e trabalho em conjunto entre bolsistas e docentes do projeto para fins de elaboração das oficinas, sessões de grupo, desenvolvimento de atividades de educação em saúde, de atividades de acessibilidade, de orientações e reuniões de equipe para o planejamento e acompanhamento das atividades desenvolvidas.

A execução de cada atividade nos polos teve por vezes o envolvimento dos alunos com deficiência junto com os educadores e familiares do PPE. A metodologia de execução dessas atividades foi baseada em entrevistas com os responsáveis pelos participantes e na realização de inventário para o levantamento de dados das principais demandas a serem desenvolvidas nas sessões de educação em saúde. Assim, com estes dados, foi possivel a realização de pesquisas para fundamentação e discussões em reuniões da equipe de trabalho para planejar e estruturar todos os encontros. Ressalta-se que as discussões de atuação eram organizadas com o foco em cada polo, destacando a singularidade de cada instituição e suas respectivas modalidades.

Cada uma das atividades citadas possibilitou uma série de ganhos para a vida acadêmica, pessoal e futuramente profissional dos extensionistas envolvidos. O processo de construção das ações foi muito semelhante a atividades de promoção de saúde realizadas por profissionais já atuantes no mercado de trabalho, além de se aproximar da realidade para implementar a lógica da proposta da promoção de saúde à população com deficiência e ao paradesporto. Isso auxiliou a potencializar a experiência dos estudantes, possibilitando a prática dos conhecimentos adquiridos e vivenciados na Universidade.

A participação no projeto de extensão pôde contribuir também para os extensionistas no exercício e na aprendizagem da escrita científica, na elaboração de artigos e de resumos para submissão de trabalhos. Durante os anos que se estenderam o projeto, os acadêmicos participaram de eventos científicos na 
Universidade (FURB), como a Mostra Integrada de Pesquisa, Ensino, Extensão e Cultura. Os graduandos também puderam desenvolver a linguagem oral no contato com a comunidade, seja em conversas de primeiro contato e formação de vínculo para apresentar as intenções do projeto, seja para exposição e desenvolvimento das propostas elaboradas.

A extensão proporciona ao acadêmico a vivência de diferentes realidades e possibilita a construção de novos conhecimentos, que não estão presentes em sala de aula. As experiências foram fundamentais para que os graduandos pudessem refletir acerca do papel da sua profissão na sociedade, bem como fortaleceu os ideais da educação em saúde, promoção de saúde, o trabalho com a singularidade e diferença e com as ações interdisciplinares.

O trabalho em equipe também foi um diferencial que agregou experiências para a vida dos envolvidos, pois exigiu diálogo, compreensão e respeito, além de estimular a otimização na divisão das tarefas - especialmente durante o segundo semestre de 2018, quando os bolsistas e voluntários entraram num processo de integração mais efetivo - e o desenvolvimento mais intenso das atividades de educação em saúde. Dessa forma, o espírito de equipe e do trabalho colaborativo foi sendo desenvolvido e construido progressivamente.

Foram encontradas algumas dificuldades durante o desenvolvimento das propostas do projeto, pois não foi possivel a execução e desenvolvimento em todos os polos pretendidos do Paradesporto Escolar. Portanto, alguns polos, em função das suas demandas específicas e ritmos diferenciados de atividades, não retornaram aos contatos da equipe para efetivar a participação no projeto e, dessa forma, não puderam ser incluidos nas práticas propostas.

Os participantes se mostraram envolvidos e interessados na maneira democrática e didática de planejamento das ações e da aplicação de conhecimento desenvolvida pela equipe do projeto. Apenas em um dos polos foi percebida algumas dificuldades de inserção e início das ações propostas pelo projeto. Contudo, com o decorrer da construção do vínculo, as dificuldades foram dissolvidas e reorganizadas dentro da singularidade da modalidade.

\section{CONSIDERAÇÕES FINAIS}

O projeto de extensão Ações de Formação, Promoção de Saúde e Acessibilidade foi o primeiro desenvolvido para o PPE de Blumenau, e provou ter um grande potencial, visto que conseguiu articular diferentes áreas de atuação na Universidade em prol de um objetivo e trabalho comuns, cada qual contribuindo através de seus potenciais técnicos. A importância deste projeto se soma à escolha da Fundação Universidade Regional de Blumenau (2020) como o Centro de Referência Paralímpico em Santa Catarina. Desta forma, exalta-se a importância e a necessidade de ações em torno do tema dos Paradesportos em Blumenau. A trajetória deste projeto demonstra ser já um grande passo neste sentido, fomentando o interesse de docentes e alunos da Universidade nesta possibilidade de extensão e pesquisa. 
Por fim, destaca-se que as estratégias desenvolvidas possibilitaram uma maior integração entre toda a comunidade atendida pelo Programa Paradesporto, assim como a formação de um postura colaborativa dos extensionistas com as demandas enfrentadas pelos participantes, favorecendo o desenvolvimento de uma formação mais humana e da transformação social, ultrapassando os muros da Universidade e agindo de maneira multi/inter/pluri/transdisciplinar no contexto histórico social com suas múltiplas determinações (Santos, 2012, p. 14). Integra-se a esse aspecto o fato de que as ações promovidas como práticas extensionistas acabaram por potencializar as aproximações dos estudantes e professores com a realidade social dos paratletas e das pessoas portadoras de deficiência em geral. 


\section{REFERÊNCIAS}

Amaral, L. A. Pensar a diferença/deficiência. (1994). Brasilia: CORDE.

Araújo T. A. M. Vasconcelos A. C. C. P. Pessoa T. R. R. F. Forte, F. D. S. (2017). Multiprofessionality and interprofessionality in a hospital residence: preceptors and residents'view. Interface (Botucatu). 21(62), 601-613. Recuperado em 14 de fevereiro, 2020, de http://www.scielo.br/scielo.php?pi$d=S 1414-32832017000300601 \&$ script=sci_abstract.

Araújo, P. F. (1997). Desporto adaptado no Brasil: origem, institucionalização e atualidade. Tese de doutorado em Estudos da Atividade Física e Adaptação, Faculdade de Educação Física, Universidade Estadual de Campinas, Campinas - SP.

Brasil. (1999). Decreto no 3.298, de 20 de dezembro de 1999. Regulamenta a Lei no 7.853, de 24 de outubro de 1989, dispõe sobre a Política Nacional para a integração da pessoa portadora de deficiência, consolida as normas de proteção, e dá outras providências. Recuperado em 4 novembro, 2019, de https://Wwww. planalto.gov.br/.

Brasil. (2012). Secretaria de Direitos Humanos da Presidência da República. Secretaria Nacional de Promoção dos Direitos da Pessoa com Deficiência. Coordenação-Geral do Sistema de Informações sobre a Pessoa com Deficiência. Cartilha do Censo 2010: Pessoas com Deficiência. Brasilia: SDH-PR/SNPD. Recuperado em 04 de novembro, 2017, de http://www.unievangelica.edu.br/ novo/img/nucleo/cartilha-censo-2010-pessoas-com-deficienciareduzido.pdf

Canguilhem, G. (1995). O Normal e O Patológico. Rio de Janeiro: Forense-Universitária.

Costa S. A. A., et al. (out./dez.2013,). Esporte adaptado: abordagem sobre os fatores que influenciam a prática do esporte coletivo em cadeira de rodas. Rev Bras Educ Fis Esporte. 27(4), 679-687.

Foucault, M. (1975). Vigiar e Punir. Petrópolis: Vozes.

Fundação Universidade Regional de Blumenau (Blumenau). FURB é Centro de Referência Paralímpico em Santa Catarina. FURB, 31 jan. 2020.

Machado, M. C. M. Chirolli, G. M. Nunes, C. R. O. (2017). Paradesporto Escolar no Município de Blumenau/SC: inclusão e acessibilidade para todos. Revista Eletrônica de Extensão.14(25),103-123.

Recuperado em 14 de fevereiro, 2020, de https://periodicos.ufsc.br/index.php/ 
extensio/article/view/1807-0221.2017v14n25p103.

Diniz, D.; Medeiros, M.; Barbosa, L. (Org). (2010). Deficiência e Igualdade. Brasilia: Letras Livres: Ed. UNB.

Santos, M. P. Contributos da Extensão Universitária Brasileira à Formação Acadêmica Docente e Discente No Século XXI: Um Debate Necessário. Conexão UEPG. 6 (1), p. 10-15, 2012.

Sawaia, B. (1999). As artimanhas da exclusão: análise psicossocial e ética da desigualdade social. Rio de Janeiro: Vozes.

Data de submissão: 14/02/2020

Data de aceite: 06/08/2020 